\title{
Allergen variability and house dust mite sensitivity in pre-school children with allergic complaints
}

\author{
Selçuk Yazıc1 ${ }^{1}$, Soner Güneş², Melike Kurtuluş-Çokboz${ }^{1}$, Özlem Kemer ${ }^{1}$, Gülce Baranlı1 \\ Sezin Aşık-Akman ${ }^{1}$, Demet Can ${ }^{1}$ \\ Departments of ${ }^{1}$ Pediatrics and ${ }^{2}$ Public Health, Balikesir University Faculty of Medicine, Ballkesir, Turkey. \\ E-mail: selcuk.yzci@gmail.com \\ Received: 10th May 2017, Revised: 26th September 2017, Accepted: 30th October 2017
}

SUMMARY: Yazıcı S, Güneş S, Kurtuluş-Çokboz M, Kemer Ö, Baranlı G, Aşık-Akman S, Can D. Allergen variability and house dust mite sensitivity in pre-school children with allergic complaints. Turk J Pediatr 2018; 60: 41-49.

The increase in the prevalence of allergic diseases in pre-school children who are often at home may be due to an increase in house dust mite sensitivity, which is rarely expected in this age group. In our study, it was aimed to investigate allergen sensitivities, especially house dust mite sensitivity in pre-school children with allergic disease complaints by skin prick test (SPT).

Two hundred and twenty children admitted to the Pediatric Allergy and Asthma Clinic of Balıkesir University between October 2015 and October 2016 diagnosed with asthma, allergic rhinitis, food allergy, atopic dermatitis or urticaria were involved in the retrospective cross-sectional study. Allergen groups used in SPT were Dermatophagoides farina (Derf), Dermatophagoides pteronyssinus (Der p), Alternaria alternata, cat epithelium, pollen mixture and food mixture.

Average age of the 220 patients was 2.98 years (2.75-3.21). SPT was positive in $55.9 \%$ of patients. Sixteen percent were monosensitized and $73.8 \%$ were polysensitized. Seventy two children (32.7\%) were sensitive to $\operatorname{Der} f$ and $67(30.4 \%)$ were sensitive to Der $p$. There was no difference between SPT positivity and gender $(p>0.05)$. Ninty-five children were diagnosed with asthma, 38 with asthma and allergic rhinitis, 63 with food allergy and 24 with urticaria and/or atopic dermatitis. SPT positivity was significantly higher in the asthma and allergic rhinitis group than other groups. As the age increased, significant increases in the sensitivities of $\operatorname{Der} f(\mathrm{p}<0.01)$, Der $p$ $(\mathrm{P}<0.01)$ and $A$. alternata $(\mathrm{p}<0.05)$ and a significant decrease for food panel sensitivity $(\mathrm{p}<0.01)$ were detected.

Even though skin and food allergies were included in our study, house dust mite sensitivity was found much higher than other studies reporting ranges between $3.5-23 \%$ in children of the same age group with mainly respiratory complaints. It is concluded that the probable reasons for this increase, especially geographical features, should be investigated in different areas and in larger number of studies.

Key words: pre-school children, allergen sensitization, house dust mite.

There has been an overall increase in the frequency of allergic diseases over the last few decades. Especially, the increase in allergic respiratory diseases has nearly doubled in the past two decades. ${ }^{1}$ This is likely to be associated with an increase in sensitivity to both indoor and outdoor allergens. ${ }^{2}$ Indoor allergens largely occupied by house dust mites are still considered to be the most important cause of sensitization in infants. ${ }^{3}$ Sensitization for indoor allergens can start in young children even under one year of age. As the age grows, the frequency of aeroallergens, especially pollen, increases and in some patient groups indoor and outdoor allergen sensitivities come close to each other at 3 years of age. ${ }^{3}$ Sensitivity to 
both groups of allergens continues to increase throughout childhood. ${ }^{2}$

Skin prick testing (SPT) is a fast, simple, low-cost, easy to apply and highly sensitive diagnostic method to evaluate environmental allergy sensitization. 2,4,5 This method is the main diagnostic tool used and has superior sensitivity and positive predictive value when compared with specific IgE blood testing. ${ }^{2}$ Accuracy of the test is $>95 \%$ and side effects are also very rare. ${ }^{4}$

One of the reasons why global warming and climate changes cause an increase in the prevalence of allergic diseases is that they increase the sensitivity of aeroallergens. The prevalence of allergic disease in the pre-school age group who are often at home, may be due to an increase in house dust mite (HDM) sensitivity, which is rarely expected in this age group. In our study, it was aimed to investigate allergen sensitivities, especially house dust mite, by SPT in pre-school children with allergic disease complaints.

\section{Material and Methods}

Two hundred and twenty children who admitted to the Pediatric Allergy and Asthma Clinic of Balıkesir University between October 2015 and October 2016 diagnosed a with asthma, allergic rhinitis, food allergy, atopic dermatitis or urticaria were involved in the resrospective cross-sectional study. The study area is characterized as Csa (warm temperature, fully humid, hot summer) according to the World Map of Köppen-Geiger climate classification. ${ }^{6}$ Required permission was obtained from the local ethics committee before the study.

None of our patients had any other systemic disease. Patients were separated into three subgroups according to age (0-1 years, 2-3 years and 4-5 years) and four subgroups according to the diagnosis (asthma, asthma + allergic rhinitis, food allergy, atopic dermatitis and/ or urticaria).

All children had typical asthmatic symptoms (wheezing, dyspnea, severe cough and/or exercise intolerance). The diagnosis of asthma was verified acoording to age-specific asthma criteria for those under 3 years of age, positive modified asthma predictive index (mAPI) was used to confirm the asthma diagnosis. For those between 3 and 5 years of age, typical asthmatic symptoms plus a positive mAPI was used. For older children of appropriate age, a positive reversibility test was also used. During the diagnostic process all patients underwent SPT. The SPT results of 220 patients with allergic symptoms were retrospectively analyzed.

\section{SPT}

Standardized SPT solutions were used. Patients, who used drugs that might affect the results before the test, were waited for appropriate time and tested. None of the patients had received local or systemic medication that could eventually affect the test. The solutions used in the test were obtained from ALK (Alk Abello SA, Calle de Miguel Fleta, 19, 28037 Madrid, Spain).
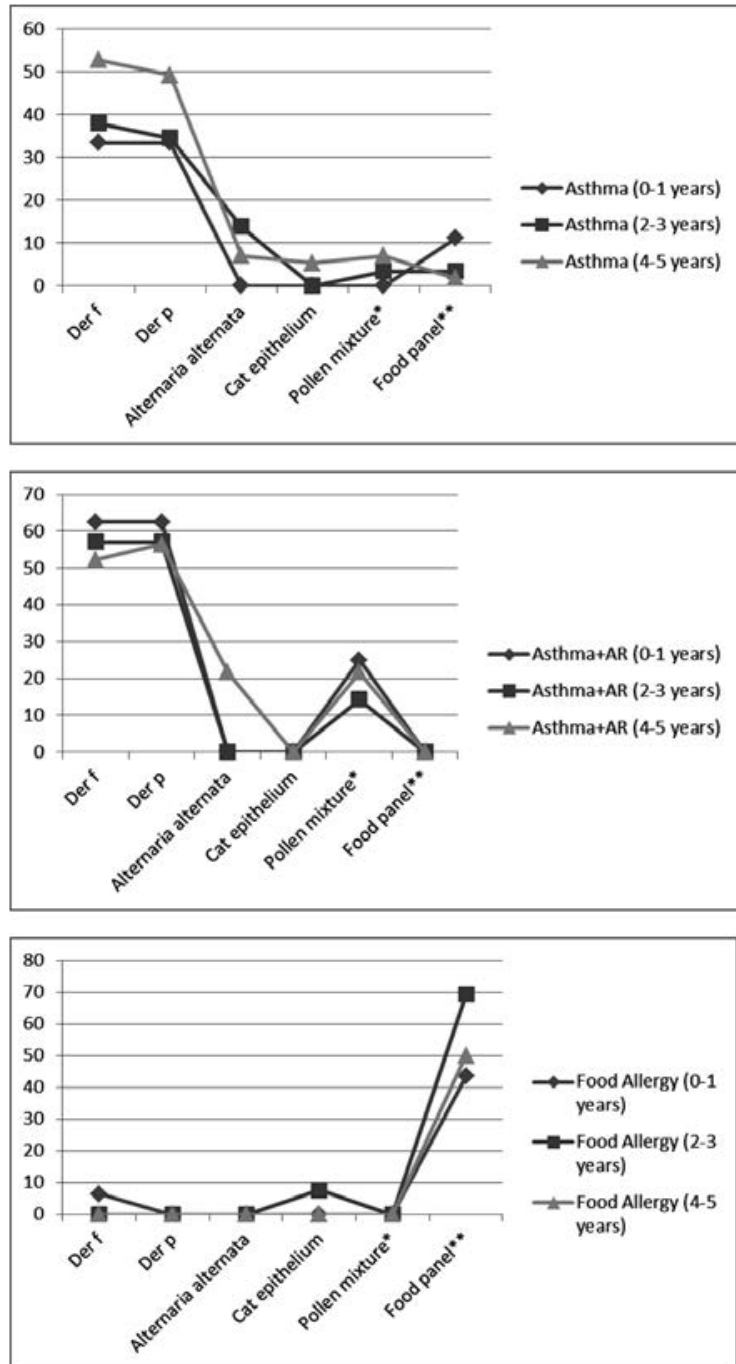

Fig. 1. Proportions (\%) of Allergens by Age Groups in Patients with Asthma, Asthma and Allergic Rhinitis and Food Allergy. 
Table I. Skin Prick Test Positivity in Patients.

\begin{tabular}{llll}
\hline Skin prick test result & Number of detected allergens & $\mathrm{n}$ & $\%$ \\
\hline Negative & - & 97 & 44.1 \\
Positive - monosensitized & 1 & 20 & 9.1 \\
Positive - polysensitized & 2 & 65 & 29.5 \\
& 3 & 18 & 8.2 \\
& 4 & 18 & 8.2 \\
& 5 & 2 & 0.9 \\
\hline
\end{tabular}

SPT was positive in $123(55.9 \%)$ patients and negative in $97(44.1 \%)$ patients. Single allergen sensitization was detected in $20(9.1 \%)$ patients. In $103(46.8 \%)$ polysensitized patients, sensitivity to two allergens in 65 patients $(29.5 \%)$, to three in 18 patients $(8.2 \%)$, to four in 18 patients $(8.2 \%)$ and to five in $2(0.9 \%)$ patients was detected.

SPT was applied to the inner surface of the forearm using the Stallerpoint prick lancet (Starallergenes, Antony, France) for the application. Histamine was used for positive control and $0.9 \%$ saline solution was used for negative control. All tests were performed by an educated nurse under the supervision of a child allergy specialist. The evaluation was done after 15 minutes. $3 \mathrm{~mm}$ and larger enduration in the test was regarded as a positive result.

All patients were tested with two different panels: 1) aeroallergen panel and 2) food panel.

Allergen groups used in SPT were Dermatophagoides farinae, Dermatophagoides pteronyssinus, Alternaria alternata, cat epithelium, pollen mixture and food mixture.

The solutions used for the test were:

\section{Aeroallergen panel:}

Positive control - Histamine $10 \mathrm{mg} / \mathrm{ml}$, Dermatophagoides farinae (Der f), Dermatophagoides pteronyssinus (Der $p$ ), Alternaria alternata, Aspergillus moulds mixture (Aspergillus amigatus, fumigatus, niger and terreus), Felis domesticus, Grass mixture - Pollens IV; (Orchard grass, Rye grass-perennial, Bluegrass, Kentucky, Fescue, Meadow, Timoty grass), Olea europea, Pollen mixture - Pollens III; (Oat, Wheat, Barley, Maize), Parietaria Judaica, Cockroach (Blatella germanica), Latex (Hevea brasiliensis).

Pollens IV (Grass mixture) and Pollens III were evaluated together as pollen mixture.

Food panel:

Positive control - Histamine $10 \mathrm{mg} / \mathrm{ml}$ (B091, $2 \mathrm{ml}$ ), Negative control $0.9 \%$ saline (B090, 2 $\mathrm{ml}$ ), White fish mixture; sea bream, anchovy, red mullet, sardine, egg white, egg yolk, cow milk, wheat flour, peanut, tomato.

\section{Statistical Analysis}

The values obtained in the study were given as mean \pm standard deviation, rate, number or percentage. The normality assumption was made by the Shapiro Wilk test. The t-test was used to compare the two groups of parameters with normal distribution for intergroup comparisons; One-way analysis of variance in more than 2 groups; Mann Whitney $\mathrm{U}$ test was used for comparison of two groups of parameters without normal distribution. Multiple comparisons were performed with the Tukey test, and the results were analyzed with Bonferroni correction. The results were evaluated in a $95 \%$ confidence interval and a significance level of $\mathrm{p}<0.05$. SPSS 22.0 package program was used for statistical analysis.

\section{Results}

The average age of the 220 patients was 2.98 years (2.75-3.21 years). Hundred and thirty one were male $(59.5 \%)$ and $89(40.5 \%)$ were female. Seventy three children between $0-1$ years of age (0-24 months), 59 children between 2-3 years of age (25-48 months) and 88 children between 4-5 years of age (49-72 months) were included in the study. Ninety five children $(43.1 \%)$ were diagnosed with asthma, $38(17.2 \%)$ with asthma and allergic rhinitis, $63(28.6 \%)$ with food allergy and 24 (10.9\%) with urticaria and/or atopic dermatitis. SPT was positive in 123 (55.9\%) patients and negative in $97(44.1 \%)$ patients. Single allergen sensitization was detected in 20 (9.1\%) patients. In 103 (46.8\%) polysensitized patients, sensitivity to two allergens in 65 
Table II. Relation of SPT Positivity with Gender and Age Groups.

\begin{tabular}{|c|c|c|c|c|c|}
\hline & \multicolumn{2}{|l|}{ Gender } & \multicolumn{3}{|l|}{ Age group } \\
\hline & $\begin{array}{l}\text { Male } \\
(n=131)\end{array}$ & $\begin{array}{l}\text { Female } \\
(\mathrm{n}=89)\end{array}$ & $\begin{array}{l}0-1 \text { year } \\
(n=73)\end{array}$ & $\begin{array}{l}2-3 \text { years } \\
(\mathrm{n}=59)\end{array}$ & $\begin{array}{l}4-5 \text { years } \\
(\mathrm{n}=88)\end{array}$ \\
\hline Test positive & 75 (57.2\%) & 48 (53.9\%) & $37(50.6 \%)$ & $31(52.5 \%)$ & $55(62.5 \%)$ \\
\hline
\end{tabular}

SPT: skin prick test.

patients $(29.5 \%)$, to three in 18 patients $(8.2 \%)$, to four in 18 patients $(8.2 \%)$ and to five in $2(0.9 \%)$ patients was detected (Table I). No adverse effect due to SPT was found in any patient.

Fifty seven $\%$ of males $(n=75)$ and $53.9 \%$ of females $(n=48)$ had tested positive. There was no difference between SPT positivity and gender $(\mathrm{p}>0.05)$. There was no difference in positivity among age groups ( $0-1$ years; $50.6 \%, 2-3$ years; $52.5 \%$ and $4-5$ years; $62.5 \%$ ) (Table II).

SPT positivity was $53.7 \%$ in the asthma group, $76.3 \%$ in the asthma and allergic rhinitis group, $50.7 \%$ in the food allergy group and $45.8 \%$ in the urticaria and/or atopic dermatitis group. Positivity was significantly higher in asthma and allergic rhinitis group than other groups $(p<0.01)$.

Seventy two children $(32.7 \%)$ were sensitive to $\operatorname{Der} f$ and $67(30.4 \%)$ were sensitive to Der $p$. Der $f$ sensitivity was $46.3 \%$ in asthma group, $55.3 \%$ in asthma and allergic rhinitis group, $4.8 \%$ in food allergy group and $16.7 \%$ in urticaria and/or atopic dermatitis group. Der $p$ sensitivity was $43.2 \%$ in asthma group, $57.9 \%$ in asthma and allergic rhinitis group and $16.7 \%$ in urticaria and/or atopic dermatitis group. Alternaria alternata sensitivity was $8.4 \%$ in asthma group, $13.2 \%$ in asthma and allergic rhinitis group and $4.2 \%$ in urticaria and/or atopic dermatitis group. Sensitivity for Def $p$ and A. alternata was not detected in food allergy group. Asthma and allergic rhinitis group had significantly higher positivity for Der $f$, Der $p$ and A. alternata than other groups (Der $f \mathrm{p}<0.01$, Der $p \mathrm{P}<0.01$, A. alternata $\mathrm{P}<0.05$. Only 4 patients $(0.02 \%)$ were sensitive to cat epithelium. (Table III).

Positive reaction to pollen mixture was $5.3 \%$ in asthma group and $21.1 \%$ in asthma and allergic rhinitis group. Children in food allergy group and urticaria and/or atopic dermatitis group did not have any positive reaction to pollen mixture. SPT positivity for food panel was $3.2 \%$ in asthma group, $49.2 \%$ in food allergy group and $20.8 \%$ in urticaria and/or atopic dermatitis group. Children with both asthma and allergic rhinitis did not have positive SPT reaction to food panel (Table III).

As the age increased, significant increases in the sensitivities of $\operatorname{Der} f(p<0.01)$, Der $p$ $(\mathrm{P}<0.01)$ and A. alternata $(\mathrm{p}<0.05)$ and $\mathrm{a}$ significant decrease for food panel sensitivity $(p<0.01)$ were detected. There was no change in sensitivities for cat epithelium and pollen mixture (Table III).

Allergen sensitivities according to diagnosis and age groups are shown in Table IV and Figure 1. There were few numbers in subgroups and no statistical evaluation was done.

\section{Discussion}

In our study, we found HDM sensitivity in pre-school children higher than expected. HDM sensitivity can be seen at a high rate even among healthy children. In a nationwide study from Korea, Kim et. al. ${ }^{7}$ found sensitivity of Der $p$ as $35.5 \%$ in males and $28.4 \%$ in females in 3840 healthy children aged 6 to 7 . Sensitivity of $\operatorname{Der} f$ was $35.6 \%$ in males and $29.0 \%$ in females and both allergens were significantly higher in males. A relationship between sensitivity and urbanization, monthly income and geographical location was found. Unfortunately, this data was not available in our present study. Torrent et al. ${ }^{8}$ studied HDM sensitivity between 0-6 ages in 3 separate centers (Ashford, United Kingdom: Menorca Island and Barcelona, Spain). Children were applied SPT at the age of 6 and Der $p$ sensitivity was found as $7.07 \%$ (Ashford, UK), $24.6 \%$ (Barcelona, Spain) and $12.4 \%$ (Menorca Island) among healthy children. In the study of Dean T. et al. ${ }^{5}$, the sensitivity of Der $p$ by SPT was found as $0.5 \%$ at age 1 , as $3.4 \%$ at age 2 and as $6.8 \%$ at age 3 . The net absolute change in sensitization in the first 3 years of 


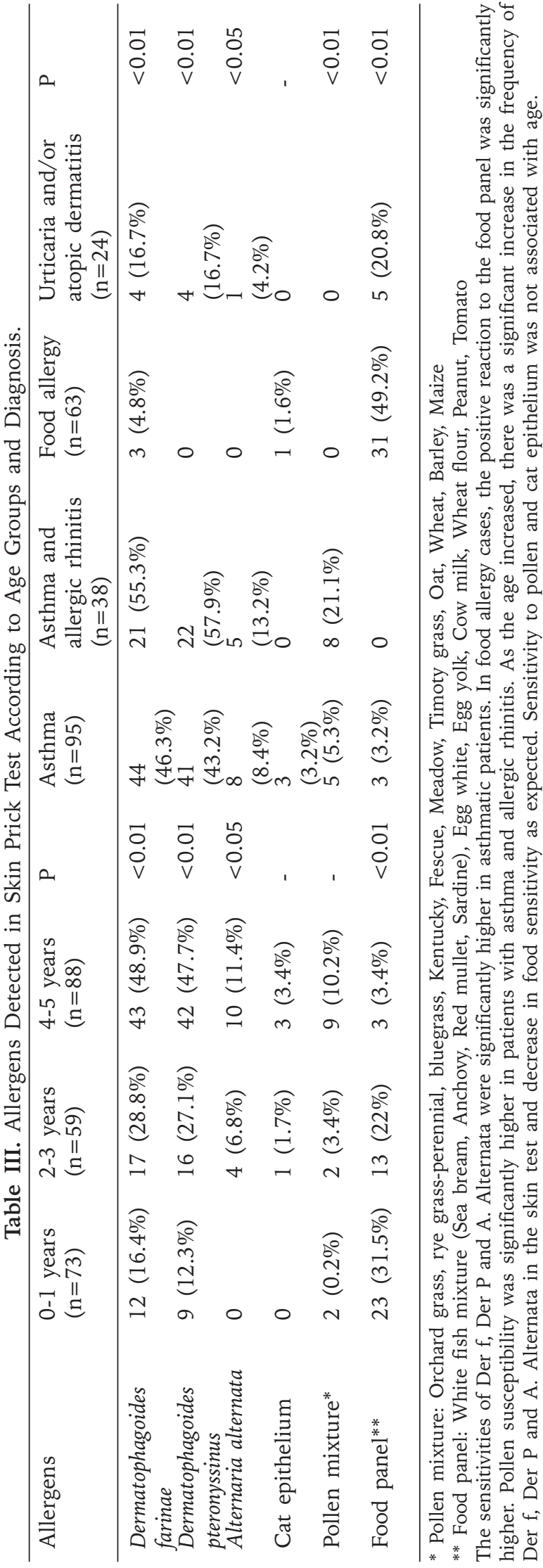

life was found to be $+6.3 \%$.

There is not a large-scale screening study in our country to investigate the sensitivity of HDM in 0-6 years old healthy children. Screening studies done on older children are also scarce. The study of Civelek et al. ${ }^{9}$ was conducted in 5 separate centers among $9-11$ years old ( $5^{\text {th }}$ grade) children $(n=6801) .35 .4 \%$ had allergic respiratory symptoms, rhinitis or eczema and $64.6 \%$ had no symptoms. 6134 children underwent SPT and the overall sensitivity of HDM (Der $f$ or Der $p$ ) were found as $7 \%$. But tests at different centers were conducted at different seasons. House dust sensitivity is given according to regions but not by symptom groups.

Kuyucu et al. ${ }^{10}$ investigated HMD sensitivity among 4th grade children (majority of children aged 9-10 years, range 8-11 years old) in Ankara. 2774 of 3426 children underwent SPT. Overal sensitivity for Der $p$ was found as $5.8 \%$, and for $\operatorname{Der} f$ as $2.8 \%$ by SPT. But in this study it is not clear whether the children had allergic symptoms.

When children with allergic symptoms are examined, HDM sensitivity differs according to the study area and diagnosis. Overall Der $p$ frequency was $31.3 \%$ and Der $f$ frequency was $28.9 \%$ in mainly adult patients with allergic symptoms in 14 European countries. ${ }^{11}$ The frequency of $\operatorname{Der} p$ and $\operatorname{Der} f$ in countries in the same climate zone with Turkey (France, Greece, Italy and Portugal; Der $p 38.1 \%$, 32.7\%, $38.9 \%$ and $22.2 \%$; Der $f 31.8 \%, 26.6 \%, 35.1 \%$ and $19.1 \%$, respectively) were close to our results. The frequency of sensitivities is not specified according to the diagnoses. In the study of Sheehan et al. ${ }^{2}$, the overall HDM positivity was found as $57.2 \%$ at $0-21$ years of age. Sensitivities for Der $p$ and Der $f$ were found as $8.2 \%$ in $0-2$ years, as $22.3 \%$ in $2-4$ years and as $37.2 \%$ in $4-6$ years. The patients were followed by the allergy center but the diagnoses and rates of sensitivities according to diseases are not expressed separately.

In the study of Lin et al. ${ }^{4}$ children with allergic rhinitis or allergic rhinitis and asthma underwent SPT at 3-5 years of age and sensitivity for Der $p$ was found as $67.5 \%$, and for $\operatorname{Der} f$ as $62.5 \%$. These results are highly compatible with our work. HDM frequency in this study was more in males. 


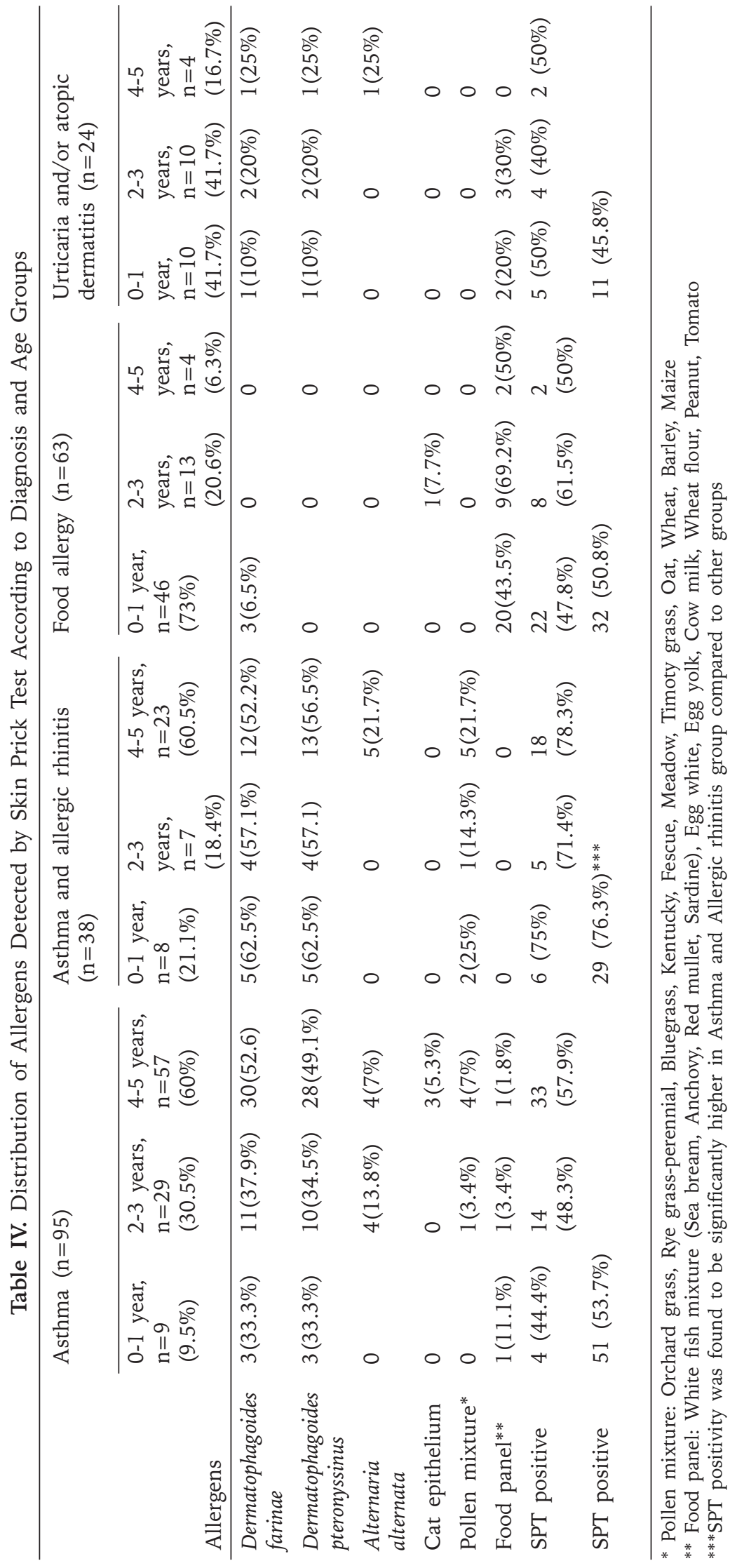




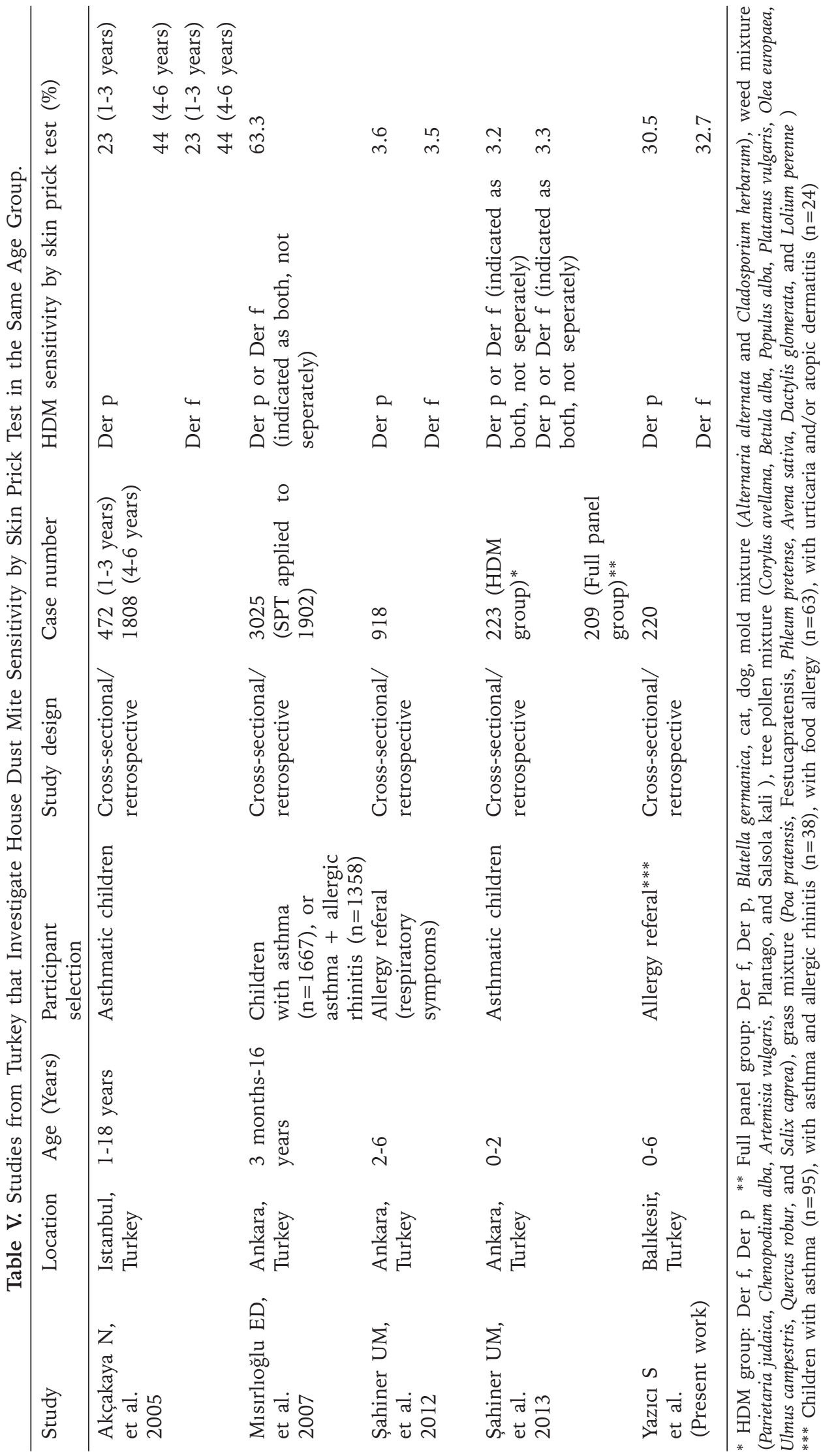


Ogershok's study ${ }^{3}$ examined 687 asthmatic children and did not find pollen sensitivity in children under one year of age. The pollen sensitivity was found as $29 \%$ at $12-24$ months. The sensitivities of indoor and outdoor allergens at 3 years of age were about the same, while outdoor allergen sensitivity, especially pollen, increased with age. In harmony, our study had few $(n=2)$ pollen allergic patients at $0-1$ age group $(0.2 \%)$ but the total number of pollen allergic patients was also small. At around 2-3 years of age, indoor allergen sensitization (Der $f 28.8 \%$, Der $p 27.1 \%$ ) was very high compared to pollen sensitivity (3.4\%).

When we compare our work with studies examining HDM sensitivity in 0-6 age children with allergic symptoms in our country, our rates seem to be quite higher (Table V). Akçakaya et al. ${ }^{12}$ reported HDM sensitivity in ashtmatic children between the ages of 1 to 18 . Sensitivity rates for both Der $p$ and for Der $f$ were $23 \%$ in 1-3 years age group and $44 \%$ in $4-6$ years age group. Similarly, overall Der $p$ sensitization was $43.2 \%$ and $\operatorname{Der} f$ sensitization was $46.3 \%$ among 0-6 years old asthmatic children $(n=95)$ in our study.

Misırlığlu et al. ${ }^{13}$ found the sensitivity of HDM as $63.3 \%$ in children with asthma $(n=1667)$, or asthma and allergic rhinitis $(n=1358)$ aged 3 months to 16 years in Ankara, Turkey. SPT was applied to 1902 of 3025 patients. This study did not specify frequency by age groups nor the frequency separately for both groups of patients.

Şahiner et al. ${ }^{14}$ found sensitivity for Der $p$ as $3.6 \%$ and for $\operatorname{Der} f$ as $3.5 \%$ in children with respiratory symptoms. Values in the 0-6 age group are quite low compared to our results, rates were higher in the 6-12 and 12-18 age range groups. In another study by Şahiner et al. ${ }^{15}, 0-2$ years old asthmatic children were examined and HDM (Der $p$ or Derf) sensitivities found in two separate panels were reported as $3.2 \%$ and $3.3 \%$.

Özkaya et al. ${ }^{16}$ studied HDM sensitivity in older children that had allergy symptoms. 512 children from Istanbul (6-16 years old) and 609 from Erzurum (6-15 years old) were included to the study. Sensitivity for $\operatorname{Der} p(72.3 \%$ in Istanbul, $22.6 \%$ in Erzurum) and for Der $f$ (71.3\% in Istanbul, $23.8 \%$ in Erzurum) were found much higher in Istanbul. This study did not specify HDM sensitivity according to the diagnosis as well.

We investigated age-specific prevalence of outdoor and indoor aeroallergen sensitization in a humid, non-polluted area and expressed HDM sensitivity according to age and diagnosis groups in 0-6 years age range. The study has some limitations as it is retrospective. HDM sensitivity is high in pre-school children with allergic complaints. As a result, $\operatorname{Der} p, \operatorname{Der} f$ and $A$. alternata sensitivities increase and food sensitivity decreases with age. An increase in pollen sensitivity, although not significant, is present. The lack of significance may be due to the small number of total pollen allergic patients $(n=13)$.

HDM sensitivity, which was reported as $3.5 \%$ in some previous studies, was found more in our study in children of the same age group with allergic symptoms. The present study is guiding the generation of SPT content in children 5 years and younger. The reasons for this increase, especially geographical features, should be investigated in other areas and in a larger number of studies. Reliable information will be available with extensive nationwide work done by cluster sampling. Many factors such as the used allergen panel content, test technique, local climate and plant flora, age, sample selection, accompanying allergic diseases etc. might affect the results of work. The increase in HDM sensitivity may be related with modern lifestyle changes that cause increased indoor lifetime for pre-school children when compared with previous generations.

\section{REFERENCES}

1. LeMasters GK, Wilson K, Levin L, et al. High prevalence of aeroallergen sensitization among infants of atopic parents. J Pediatr 2006; 149: 505-511.

2. Sheehan WJ, Rangsithienchai PA, Baxi SN, et al. Agespecific prevalence of outdoor and indoor aeroallergen sensitization in Boston. Clin Pediatr 2010; 49: 579-585.

3. Ogershok PR, Warner DJ, Hogan MB, et al. Prevalence of pollen sensitization in younger children who have asthma. Allergy Asthma Proc 2007; 28: 654-658.

4. Lin H, Lin R, Li N. Sensitization Rates for Various Allergens in Children with Allergic Rhinitis in Qingdao, China. Int J Environ Res Public Health 2015; 12: 10984-10994.

5. Dean T, Venter C, Pereira B, et al. Patterns of sensitization to food and aeroallergens in the first 3 years of life. J Allergy Clin Immunol 2007; 120: 1166-1171. 
6. Kottek M, Grieser J, Beck C, et al. World map of the Koeppen-Geiger climate classification updated. Meteorol Z 2006; 15: 263.

7. Kim J, Hahm MI, Lee SY. Sensitization to aeroallergens in Korean children: a population-based study in 2010 . J Korean Med Sci 2011; 26: 1165-1172.

8. Torrent M, Sunyer J, Garcia R. et. al. Early-life allergen exposure and atopy, asthma, and wheeze up to 6 years of age. Am J Respir Crit Care Med 2007; 176 : 446453.

9. Civelek E, Sahiner UM, Yüksel H, et. al. Prevalence, burden, and risk factors of atopic eczema in schoolchildren aged 10-11 years: a national multicenter study. J Investig Allergol Clin Immunol 2011; 21: 270-277.

10. Kuyucu S, Saraçlar Y, Tuncer A, et al. Determinants of atopic sensitization in Turkish school children: effects of pre- and post-natal events and maternal atopy. Pediatr Allergy Immunol 2004; 15: 62-71.

11. Burbach GJ, Heinzerling LM, Edenharter G. GA(2) LEN skin test study II: clinical relevance of inhalant allergen sensitizations in Europe. Allergy 2009; 64: 1507-1515.
12. Akcakaya N, Cokugras H, Camcioglu Y, Ozdemir M. Skin test hypersensitivity for childhood asthma in Istanbul during a period of 16 years. Allergol Immunopathol 2005; 33: 15-19.

13. Dibek Mısırlıoğlu D, Reha Cengizlier M. Skin prick test results of child patients diagnosed as bronchial asthma. Allergol Immunopathol (Madr) 2007; 35: 2124.

14. Şahiner UM, Civelek E, Yavuz ST, et al. Skin prick testing to aeroallergen extracts: what is the optimal panel in children and adolescents in Turkey? Int Arch Allergy Immunol 2012; 157: 391-398.

15. Sahiner UM, Buyuktiryaki AB, Yavuz ST, et al. The spectrum of aeroallergen sensitization in children diagnosed with asthma during first 2 years of life. Allergy Asthma Proc 2013; 34: 356-361.

16. Ozkaya E, Sogut A, Küçükkoç M, et al. Sensitization pattern of inhalant allergens in children with asthma who are living different altitudes in Turkey. Int J Biometeorol 2015; 59: 1685-1690. 